man I have known could have survived. After losing one companion and practically all the party's food down a crevasse and seeing a second companion die of starvation and over-exertion by his side, he cut his tent down to half a tent, his sledge down to half a sledge and trudged into his headquarters after three further weeks man-hauling alone on just enough food to keep body and soul together.

It is a measure of Mawson's courage and determination that his second enforced year's stay saw the carrying through of scientific work as fine in quality as that of the preceding year when all was going well. A stream of memoirs that kept the Australian Government Press busy off and on for forty years is one fitting tribute to an enterprise brilliantly planned and executed in the face of exceptional difficulties.

In the years following 1913 Mawson did outstanding work as field geologist and teacher; but Antarctic science remained a major interest throughout a long life that came to an end on October 15. $\mathrm{H}_{\Theta}$ went to Antarctica again in 1929 and 1930, when he discovered MacRobertson Land, Queen Elizaboth Land and the Mackenzie Sea, using a seaplane to increase his range of action. Since the Second World War he has been a driving force behind the Australian Antarctic organization, A.N.A.R.E. When Prince Philip visited Australia in Britannia in 1956, it was Mawson who took the chair at the Antarctic symposium that was one important feature of the Melbourne programme, and the paper he delivered showed that his interest was as strong as ever and his intellect as keen. In courage, determination, singleness of purpose, breadth of scientific interest and quality of mind, he was Australian man at his best and he will be sorely missed. No one will regret his passing on more than the few surviving companions of his early adventurous days. Raymond Priestley

\section{Prof. F. A. Paneth, F.R.S.}

Workers throughout the world in many branches of science have learned with deep regret of the death in Vienna on September 17 of Dr. Friedrich Adolph Paneth, a director in the Max-Planck-Institut für Chemie in Mainz and emeritus professor of chemistry in the University of Durham.

Paneth was born in 1887 in Vienna, where his father was lecturer in physiology in the University. After studying science at the University of Vienna, he moved to Munich and, later, to Glasgow, where he worked for a year in the laboratory of Frederick Soddy. In 1912 he was appointed assistant at the Vienna Radium Institute, and six years later to a chair at the Prague Institute of Technology ; during the ensuing fifteen years he held similar posts in the Universities of Hamburg, Berlin and Königsberg. The events of 1933 in Germany caused him to leave that country and to seek refuge in London, where accommodation was found for him at the Imperial College of Science and Technology; the welcome he received there was later put on a more formal basis by his appointment to a readership in atomic ehemistry. In 1939, Paneth was appointed to the chair of chomistry at Durham, from which he retired in 1953 on reaching the age-limit. Even then he was not content to give up active scientific work, but returned to Germany to take up the post at Mainz which he held until his death.

Paneth's early education had been broadly basedto the end of his life he retained a keen interest in the humanities-and he was never in danger of too narrow a specialization in his work. His first major contribution, dating from his time at the Vienna Radium Institute, was made when he and Hevesy laid the foundations of the modern use of radioactive isotopes as tracers. At that time, of course, only lead and bismuth among the common elements were available in a usable radioactive form; but Hevesy and Paneth not only demonstrated that such materials could be used to follow the details of chemical reactions, but also went on to investigate in some detail the behaviour of trace quantities of such substances in precipitation, adsorption, electrochemical and colloid experiments.

After leaving Vienna, Paneth continued with this fundamental radiochemical work, but he was also led, by one of those almost accidental steps which not infrequently precede big developments in science, to the experiments which conclusively demonstrated the transitory existence of the simple aliphatic free radicals-perhaps his most important contribution to pure chemistry. He had been using the extreme sensitivity of the radioactive indicator technique to demonstrate the existence of the hydrides of lead and bismuth, and went on, with Fiofeditz, to examine the pyrolysis of tetramethyl lead carried, in a stream of hydrogen, rapidly through a heated quartz tube. They demonstrated, in a classic series of experiments, that the immediate products of the pyrolysis are metallic lead and free methyl radicals, and established a procedure that has since found wide use in studies of free radicals. During this period he was also refining the technique of measurement of the very small quantities of helium formed - as $\alpha$-particles -in radioactive decay processes. This work was continued after Paneth's arrival in Britain, and increasingly applied to the problem of 'age determination', especially of meteoritic materials. He began also to turn his attention to some chemical aspects of meteorology and, in collaboration especially with E. Glueckauf, much careful work was done on the concentrations of the minor constituents of the atmosphere.

On account of the second World War, Paneth achieved little in Durham until 1945, when he returned from Montreal, where he had spent two years with the joint British-Canadian Atomic Energy Laboratory to which he had been seconded. He was determined to set up in Durham a research laboratory devoted to radiochemical studies and, with characteristic indifference to the administrative difficulties of the immediate post-war period, he achieved his aim : the Londonderry Laboratory for Radiochemistry was formally opened in June 1947. Here the work on the rare gases, which was now Paneth's main interest, was pressed forward, with especially intensive work on the problem of the ages of meteorites. The atmospheric work was also continued, in collaboration with the U.S. Air Force, which carried out experimental rocket firings to obtain samples of air from very great heights for analysis.

Paneth was keenly interested in the history and philosophy of science (and, indeed, in philosophy in wider contexts) and was often consulted about the naming of newly discovered elements, and other questions of chemical nomenclature. As president (from 1949 until 1955) of the Joint Commission on Radioactivity of the International Council of Scientific Unions, he provided a useful link between the physical and chemical approaches to problems of standardization in radioactivity. In 1926 he had 
been George Fisher Baker Lecturer at Cornell University, and his lectures formed the basis of his book, "Radioelements as Indicators"; with Hevesy he was the author also of "A Manual of Radio. activity", long regarded as a standard work on classical radioactivity. Paneth was elected to the Royal Society in 1947, and was honoured by many other learned societies, both in Britain and abroad.

It is clear that on his record as a scientist, Paneth is assured of a place in history, but something remains to be said of him as a person. He would not have counted himself a great experimentalist; rather his contribution was to create the conditions in which good work could be done-by selecting a happy team of collaborators, ensuring that they were not impeded by lack of equipment, and providing the necessary intellectual stimuli. He knew how to delegate responsibilities, and his colleagues knew that they could rely on his loyal support in anything they did on behalf of the Laboratory. Paneth was a natural linguist, and his command of English was extraordinarily good for one thrust into its use at so late a stage in his career. He was greatly in demand as a lecturer, and had a particular flair for exposition at the non-specialist level. These lectures were prepared with great care, and they were masterpieces of presentation, with just the correct blend of history, philosophy, wit, and hard scientific fact.

Paneth was a man of great personal charm-he can, for example, have had fow peers in the matter of persuading museum curators to part with samples of meteorites-and he was blessed with a keen sense of humour. The numerous visitors to his Laboratory who enjoyed the hospitality provided at his home will long cherish memories of evenings of stimulating and amusing conversation. Their deepest sympathy will be extended to his widow, and to the son and daughter who survive him. $\quad$ G. R. Martin

\section{NEWS and VIEWS}

\section{Nobel Prize for Chemistry :}

Dr. F. Sanger, F.R.S.

Dr. Frederick SANGer, who has been awarded the Nobel Prize for Chemistry for 1958, is a member of the staff of the Medical Research Council, and has spent the whole of his research life in the Department of Biochemistry, University of Cambridge, the University of which he was an undergraduate. The award has been made for his researches on the structure of the protein hormone insulin, the elucidation of which he completed in 1955, at the age of thirty-seven, after ten years of intensive research. The methods which he developed for this purpose are a model of effectiveness. When he began his investigations on insulin, Dr. Sanger first devised the use of dinitrofluorobenzene for the identification and estimation of the free amino-groups of proteins or peptides, and this method has since been widely adopted. By 1949 Sanger had shown that oxidation of insulin with performic acid, to break disulphite bonds, led to two separate fractions. Partial hydrolysis of the two separated portions with acid, and later with enzymes, yielded a series of peptides which he isolated by chromatography. The application of the dinitrofluorobenzene method to the peptides enabled Sanger and his colleagues to determine the sequence of amino-acids in the peptides, and so to deduce the sequences in the two large portions which had been formed by the oxidative fission of the insulin molecule. The results were such that a unique sequence of amino-acids could be ascribed to each of the two portions of the molecule. The determination of the position of the disulphide linkages involved the subjection of insulin to partial hydrolysis by enzymes under conditions in which the disulphide bonds remained stable. The cystinecontaining peptides in the hydrolysate were separated and their structures determined by the methods he had previously developed. The structures of the cystine peptides which thus were elucidated showed that only one solution was possible to the problem of the distribution of the sulphide bonds in insulin. Two of these formed junctions between the two main peptide chains of the molecule, while a third disulphide link spanned four amino-acid residues in a manner similar to that previously deduced by du Vigneaud and his colleagues for the hormones oxytocin and vasopressin. Afterwards, Sanger and his colleagues showed that certain of the amino-acids within this intra-chain disulphide link differ in insulins from different species. Dr. Sanger's methods and example have stimulated much research in the investigation of protein structure, the limits of which have yet to be visualized, and they make clear the possibility that insulin may be completely synthesized in the laboratory, although this is unlikely to occur for some time to come.

Nobel Prize for Physics: Dr. P. A. Čerenkov, Dr. I. M. Frank and Dr. I. Tamm

The award of the Nobel Prize for Physics for 1958 to the Russian physicists, P. A. Cerenkov, I. M. Frank and I. Tamm, for their work in the discovery and interpretation of the nature of Cerenkov radiation, is a fitting recognition of a scientific advance which has acquired great importance for experimental highenergy nuelear physics and cosmic rays. Cerenkov's contribution was to make, in 1934, a detailed study of the light emitted by liquids when they were exposed to radiations from radioactive substances. That certain substances were fluorescent under the influence of such radiations had been known since the days of Becquerel, but whereas fluorescent light depended markedly on the chemical nature of the substance, a weak residual light was found to be emitted even when all traces of fluorescent substances had been removed. This light was named the Cerenkov light; it was given a theoretical interpretation by Frank and Tamm in 1937. Frank and Tamm showed, on the basis of classical electromagnetic theory, that a charged particle travelling through a medium with a velocity greater than the velocity of light in that medium gives rise to an electromagnetic shock wave. This shock wave, which is analogous to the bow wave produced in water by a fast-moving ship, constitutes the Cerenkov radiation. Čerenkov light can only be observed in a medium which has a sufficiently high refractive index to bring the velocity of light in the medium below that of the charged partiele; and it is emitted (like a bow-wave on water) at a definite angle to the direction of motion of the charged particle, the angle 